\section{To: (Receiving Organization)}

LMHC Characterization Engineering

5. Proj./Prog./Dept/Div.:

Characterization Project

8. Originator Remarks:

3. From: (Originating Organization)
Characterization Engineering
6. Design Authority/Design Agent/Cog. Engr.:
GP Janicek/BL Coverdell/RN Dale

GP Janicek/BL Coverdell/RN Dale

Supporting document submitted for review and approval prior to release.

11. Receiver Remarks:

IlA. Design Baseline Document? [] Yes [X] No

\begin{tabular}{|c|c|c|c|}
\hline \multicolumn{4}{|c|}{ 4. Related EDT No.: } \\
\hline \multicolumn{4}{|c|}{$\begin{array}{r}\text { 7. Purchase Order No.: } \\
\text { N/A }\end{array}$} \\
\hline \multicolumn{4}{|c|}{$\begin{array}{r}\text { 9. Equip./Component No.: } \\
\text { N/A }\end{array}$} \\
\hline \multicolumn{4}{|c|}{ 10. System/Bldg./Facility: } \\
\hline \multicolumn{4}{|c|}{$\begin{array}{r}\text { 12. Major Assm. Dwg. No.: } \\
\text { N/A }\end{array}$} \\
\hline \multicolumn{4}{|c|}{ 13. Permit/Permit Application No.: } \\
\hline \multicolumn{4}{|c|}{ 14. Required Response Date: } \\
\hline \multicolumn{4}{|c|}{ ASAP } \\
\hline (F) & (G) & $(\mathrm{H})$ & (I) \\
\hline $\begin{array}{l}\text { Approval } \\
\text { Designator }\end{array}$ & $\begin{array}{l}\text { Reason } \\
\text { for Trans- } \\
\text { mittal }\end{array}$ & $\begin{array}{l}\text { Origi- } \\
\text { nator } \\
\text { Dispo- } \\
\text { sition }\end{array}$ & $\begin{array}{l}\text { Receiver } \\
\text { Dispo- } \\
\text { sition }\end{array}$ \\
\hline SQ & 1 & 1 & \\
\hline & & & \\
\hline & & & \\
\hline & & & \\
\hline . & $\cdots$ & & \\
\hline Dispositio & (H) \& (I) & & \\
\hline & $\begin{array}{l}\text { Reviewed } \\
\text { Reviewed } \\
\text { Receipt ac }\end{array}$ & $\begin{array}{l}\text { /commen } \\
\text { comment } \\
\text { lowledged }\end{array}$ & \\
\hline
\end{tabular}

15.

DATA TRANSMITTED

\begin{tabular}{|c|c|c|}
\hline $\begin{array}{c}\text { (A) } \\
\text { Item } \\
\text { No. }\end{array}$ & \multicolumn{2}{|c|}{ (B) Document/Drawing No. } \\
\hline 1 & HNF-3707 & \\
\hline & & \\
\hline & & \\
\hline & & \\
\hline & & \\
\hline 16. & KEY & \\
\hline Approval Designator (F) & \\
\hline $\begin{array}{l}\text { E, S, Q, D or N/A } \\
\text { (see WHC.CM-3-5, Sec. 12.7) }\end{array}$ & $\begin{array}{l}\text { 1. Approval } \\
\text { 2. Release }\end{array}$ \\
\hline
\end{tabular}

Reason for Transmittal (G)

4. Review

5. Post-Review

6. Dist. (Receipt Acknow. Required)

(E) Title or Description of Data Transmitted NGINEERING STUDY OF $500 \mathrm{ML}$ SAMPLE BOTTLE TRANSPORTATION METHODS

17. SIGNATURE/DISTRIBUTION

(See Approval Designator for required signatures)

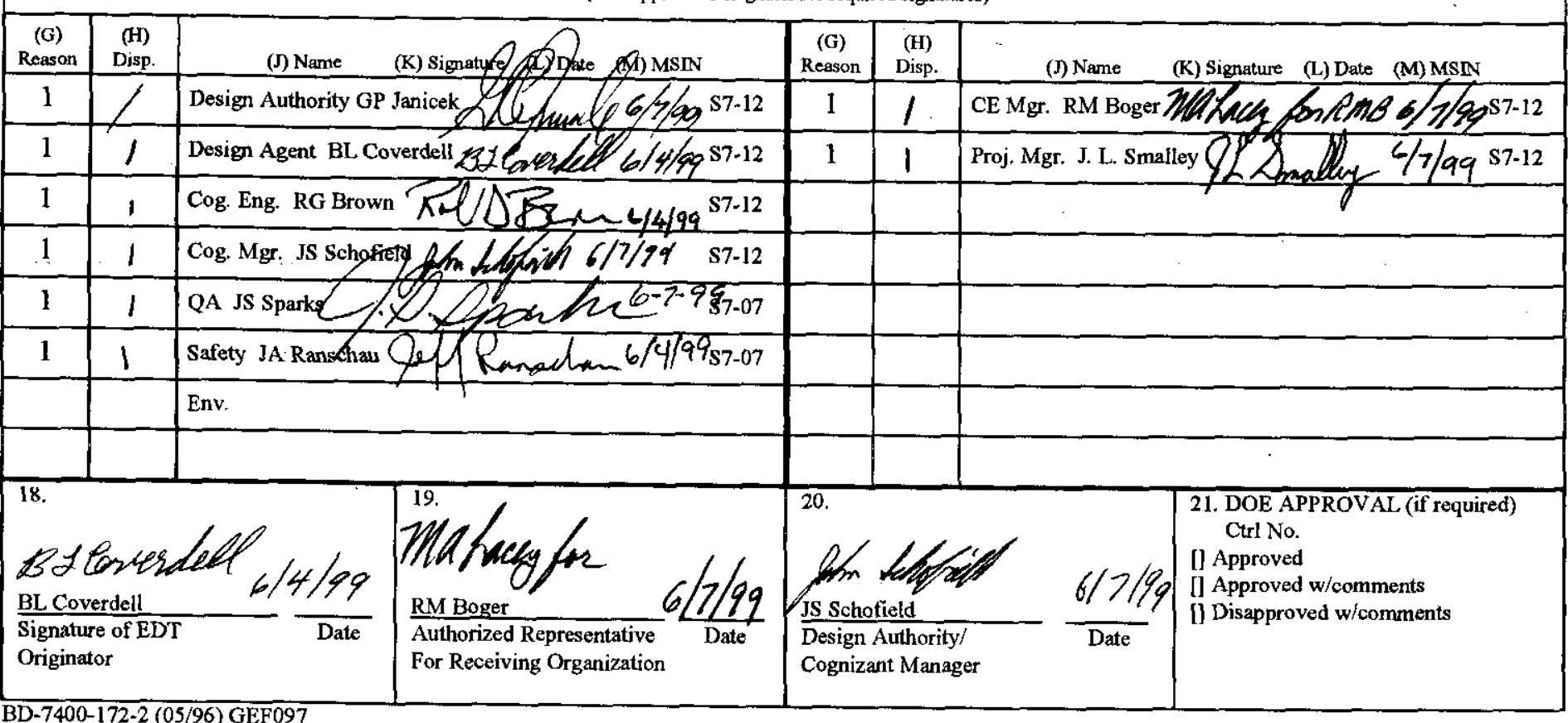


HNF-3707, Rev. 0

\title{
ENGINEERING STUDY OF 500 ML SAMPLE BOTTLE TRANSPORTATION METHODS
}

\author{
R. M. Boger \\ Prepared by Lockheed Martin Hanford Company \\ 2400 Stevens \\ Richland, WA 99352 \\ U.S. Department of Energy Contract DE-AC06-96RL13200
}

EDT/ECN: 620263

Org Code: 74900

B\&R Code: EW3120074

UC: 2070

Charge Code: CACN: $102613 \quad$ COA: EI00

Total Pages: 1515

Key Words: Characterization Project, Sampling, Shipping Pig, Cask, Hedgehog, SAFESEND

Abstract: This engineering study reviews and evaluates all available methods for transportation of $500-\mathrm{mL}$ grab sample bottles, reviews and evaluates transportation requirements and schedules and analyzes and recommends the most cost-effective method for transporting 500-mL grab sample bottles.

TRADEMARK DISCLAIMER. Refetence herein to any specific commercial product, process, or service by trade name, trademark, manufacturer, or otherwise, does not necessarily constitute or imply its endorsement, recommendation, or favoring by the United States Government or any agency thereof or its contractors or subcontractors.

Printed in the United States of America. To obtain copies of this document, contact: Document Control Services, P.O. Box 950, Mailstop H6-08, Richland WA 99352, Phone (509) 372-2420; Fax (509) 376-4989.
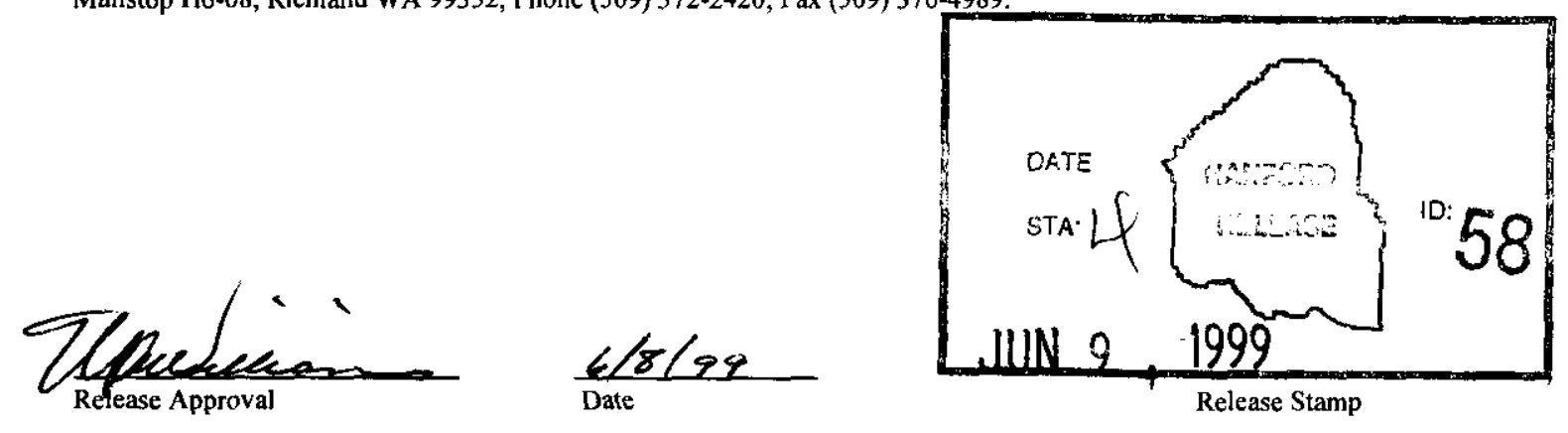

\section{Approved for Public Release}




\section{ENGINEERING STUDY OF 500 ML SAMPLE BOTTLE TRANSPORTATION METHODS}

Prepared for Lockheed Martin Hanford Corporation Characterization Engineering Group

By

B. L. Coverdell

COGEMA Engineering Corporation

April 1999 


\section{TABLE OF CONTENTS}

1.0 OBJECTIVE

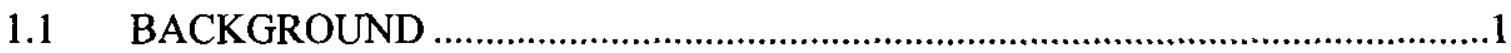

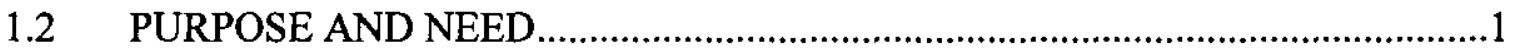

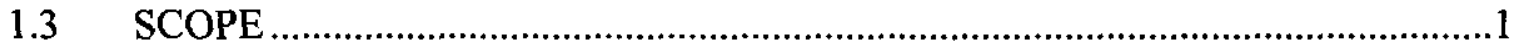

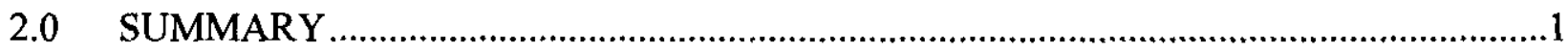

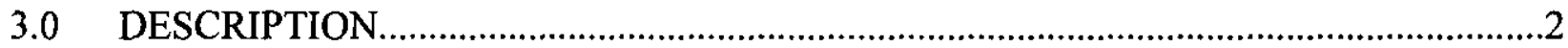

3.1 PIG SHIPPING CONTAINER SYSTEM …….................................................2

3.2 DOORSTOP SHIPPING CONTAINER SYSTEM ................................................

3.3 HEDGEHOG SHIPPING CONTAINER SYSTEM …......................................

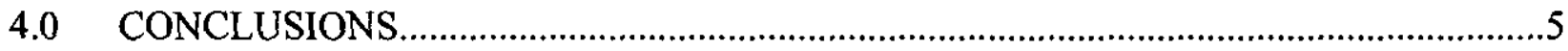

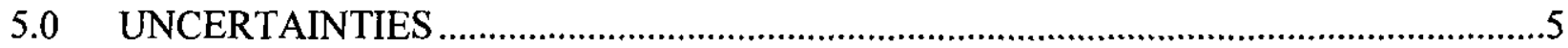

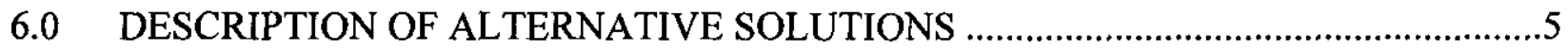

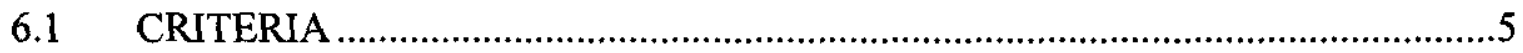

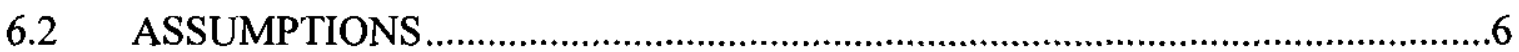

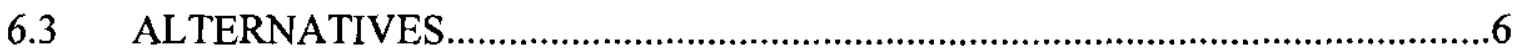

7.0 DISCUSSION OF PREFERRED ALTERNATIVE SOLUTION …….............................9

8.0 NO ACTION ALTERNATIVE .....................................................................................

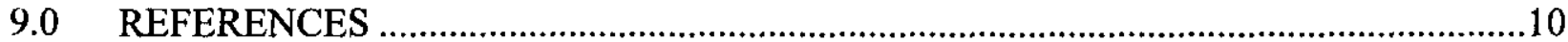

APPENDIX A: SHIPPING CONTAINER SYSTEM COMPARISON.................................... A-1

\section{TABLE OF FIGURES}

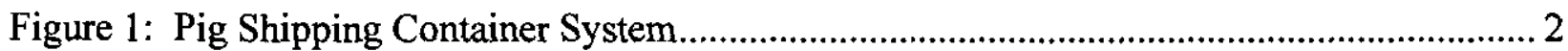

Figure 2: Doorstop Shipping Container System ………....................................................... 4

Figure 3: PAS-1 Steel Pig Cost Estimate (in Man Hours).............................................................. 8 


\subsection{OBJECTIVE}

\subsection{BACKGROUND}

Currently on the Hanford Site, efforts are being made to determine the chemical components that makeup the radioactive waste contained in the 177 waste tanks. The tanks containing supernatant or sludge can be sampled by taking "grab samples" from the tank. Grab samples are obtained by lowering the grab sample assembly on a wire rope. The assembly contains a plugged grab sample bottle that can be unplugged remotely. After the assembly is lowered to a specified depth, the plug is removed, the sample bottle is allowed to fill and then the assembly is raised. Within a glovebag, the grab sample bottle is removed from the assembly, the sample bottle is capped and, depending on the size of the grab sample bottle, it is either placed in a Sample Pig or a SAFESEND ${ }^{\circledR 1}$. Finally, either the Sample Pig or SAFESEND is placed in a Pig Shipping Container, which is located in the bed of a heavy-duty pickup truck. The grab sample is then transported to an on-site chemical laboratory for analysis.

Current site practice is to transfer $125 \mathrm{ml}$ grab sample bottles using a Sample Pig. Due to the age of the Sample Pigs, the lead liner is beginning to slump. This makes it difficult to insert and remove grab sample bottles. The chemical laboratories have expressed concerns about the possibility of breaking grab sample bottles due to the difficulties of removal.

$500 \mathrm{ml}$ grab sample bottles are transferred using the SAFESEND shipping container. The SAFESEND has no shielding, resulting in high whole body exposure to the field sample crews. After several uses, the lid of the SAFESEND breaks rendering it unusable. The manufacture no longer makes SAFESENDs. Also, the cost of shipping grab samples could be reduced if the size and number of samples shipped per truck were increased.

\subsection{PURPOSE AND NEED}

This engineering study reviews and evaluates all available methods for transportation of $500 \mathrm{ml}$ grab sample bottles. It evaluates transportation requirements and schedules and, finally, the study analyzes and recommends the most cost-effective method for transporting $500 \mathrm{ml}$ grab sample bottles.

\subsection{SCOPE}

This study focuses primarily on the shipment sludge or supernatant using $125 \mathrm{ml}$ or $500 \mathrm{ml}$ bottles grab samples on the Hanford site.

\subsection{SUMMARY}

\footnotetext{
${ }^{1}$ SAFESEND' is a registered trademark of the $3 \mathrm{M}$ Corporation.
} 
This study reviewed and evaluated all methods of transporting $500 \mathrm{ml}$ grab sample bottles and determined that the PAS-1 Steel Pig is the most cost-effective method. For this reason, it is recommended that the PAS-1 Steel Pig be used to replace the SAFESENDs. The requirements and analysis used to draw this conclusion are discussed in the remaining sections of this document.

\subsection{DESCRIPTION}

Listed below are three shipping container systems available for use on the Hanford Site. Some of these systems can be used for transportation of several types of shipping containers.

\subsection{PIG SHIPPING CONTAINER SYSTEM}

The Pig Shipping Container System (Figure 1) is an existing packaging system certified for use on the Hanford Site. The major components of the Pig Shipping Container System consists of the N-55 Overpack, a DOT 208 L drum, the Pig Shipping Container and one of the following; a Sample Pig, SAFESEND or PAS-1 Steel Pig.

\section{Pig Shipping Container System}

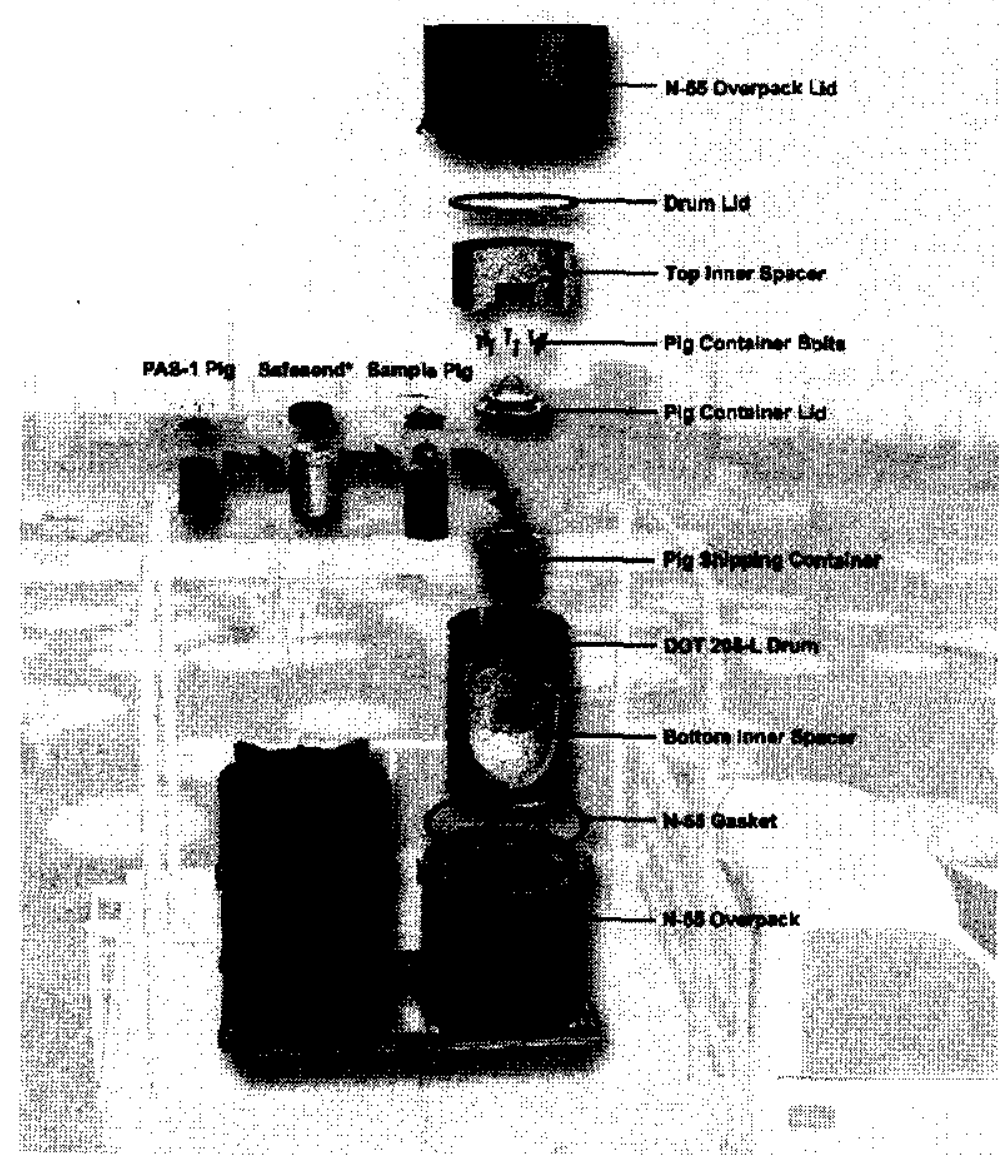


The PAS-1 Steel Pig and the Sample Pig both provide additional shielding, however, the SAFESEND does not. Also, dedicated vehicles are used for transportation of the Pig Shipping Container System.

\subsubsection{SAMPLE PIG}

The Sample Pig is used in conjunction with the Pig Shipping Container System for the transportation of $125 \mathrm{ml}$ grab sample bottles only. A Sample Pig can hold a single $125 \mathrm{ml}$ grab sample. This configuration is currently certified for the shipment of two $125 \mathrm{ml}$ grab sample bottles per Safety Analysis Report for Packaging (On-site) Sample Pig Transportation System (FDH 1998c).

The Sample Pig is constructed from 304L stainless steel with a $4.8 \mathrm{~cm}$ (1.9 in) poured lead shielding. A quick-release safety pin holds the lid in place. The Sample Pig lid is constructed from 304 stainless steel pipe with an 11-gauge 240 stainless steel sheet covering each lid. Over a period of time, the lead lining has slumped making it difficult to insert and remove sample bottles.

\subsubsection{SAFESEND}

The SAFESEND is mainly used to transfer $500 \mathrm{ml}$ grab sample bottles, however, it can also be used to transfer $1 \mathrm{~L}$ grab sample bottles. It is constructed from plastic and has a screw-on locking plastic lid. The inside of the SAFESEND is partially filled with an absorbent material used to safely contain any spills should they occur. Because the SAFESEND is constructed using lightweight, low strength material it provides no additional shielding to the Pig Shipping Container System. For this reason, when the SAFESEND is used with the Pig Shipping Container System it is certified per FDH 1998c for the transfer of a maximum $1 \mathrm{~L}$ of limited Type $\mathrm{B}$ radioactive materials.

\subsection{DOORSTOP SHIPPING CONTAINER SYSTEM}

The Doorstop Shipping Container System (Figure 2) consist of an N-55 Overpack with up to seven Doorstop Shipping Containers inside. Each Doorstop Shipping Container System has container called a Paint Can inside. This system is currently certified for transportation of any Type B radioactive material in $125 \mathrm{ml}$ grab sample bottles (max). Physically, the Paint Can may accommodate a $500 \mathrm{ml}$ grab sample bottle, however, this configuration would require modification to the Paint Can. Any modifications to the Paint Can would require a reduction in the amount of shielding. The Paint Can would also need to be re-certified for transportation of $500 \mathrm{ml}$ grab sample bottles. These changes may or may not meet the sampling requirements. Dedicated vehicles are used for transportation of the Doorstop Shipping Container System. 
HNF-3707, Rev. 0

\section{Doorstop Shipping Container System}

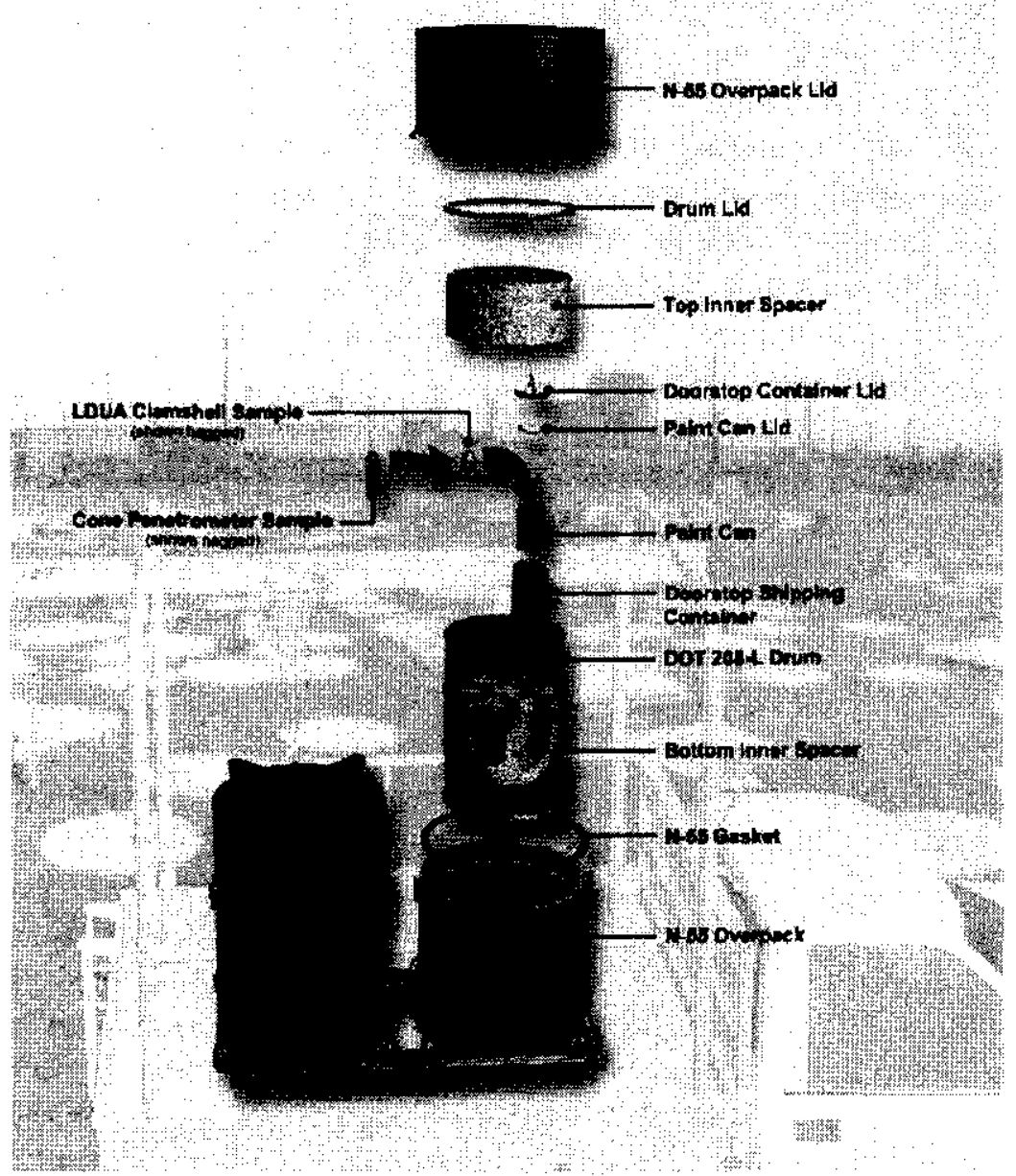

Figure 2: Doorstop Shipping Container System

\subsection{HEDGEHOG SHIPPING CONTAINER SYSTEM}

The Hedgehog Shipping Container System is capable of transporting $30 \mathrm{ml}$, $125 \mathrm{ml}, 250 \mathrm{ml}$ and $1 \mathrm{~L}$ grab sample bottles. Each of the grab sample bottles is placed in a SAFESEND and the SAFESEND is placed in a Hardigg Case $\otimes^{2}$. Per WHC 1995, the Hedgehog Shipping Container System can only use the SAFESEND A limited number of times. The Hedgehog Shipping Container System has been tested and certified by the U.S. Department of Energy (DOE) as a U.S. Department of Transportation (DOT) Specification 7A Type A packaging for radioactive materials (WHC 1995). Few tanks on the Hanford Site meet the shipping requirements of Type A radioactive material. If the SAFESEND is used with the Shipping Pig the combination is certified for transferring limited Type B radioactive materials.

\footnotetext{
${ }^{2}$ Hardigg Case is a registered trademark of Hardigg Industries, Inc.
} 


\subsection{CONCLUSIONS}

Review of possible transportation methods for $500 \mathrm{ml}$ grab sample bottles has determined that using the PAS-1 Steel Pig in conjunction with the Pig Shipping Container System is the best solution. The PAS-1 Steel Pig provides additional shielding for transportation of all Type B radioactive material (Supernatant and Sludge). This feature will allow for the transportation of two $500 \mathrm{ml}$ grab sample bottles per vehicle or four $125 \mathrm{ml}$ grab sample bottles per vehicle. Unlike many of the transportation methods, the PAS-1 Steel Pig does not have a finite life and can quickly be fabricated and/or procured. Most importantly, the PAS-1 Steel Pig can be used with the existing Pig Shipping Container System with only minor modifications. By writing an Engineering Change Notice against FDH 1998c the PAS-1 Steel Pig can legally be used for transportation of $500 \mathrm{ml}$ grab sample bottles on the Hanford Site. Finally, the total cost for using the PAS-1 Steel Pig for transportation of $500 \mathrm{ml}$ grab sample bottles is conservatively estimated at 945 man-hours or $\$ 95 \mathrm{k}$.

\subsection{UNCERTAINTIES}

The number and volume of grab samples to be taken over the next several years was the only uncertainty found. There are several driving factors for taking grab samples and the volume of those samples. Several samples are taken for the following;

- Waste transfer compatibility,

- Evaporator support,

- $\quad$ Privatization support.

\subsection{DESCRIPTION OF ALTERNATIVE SOLUTIONS}

\subsection{CRITERIA}

\subsubsection{TRANSPORTATION REQUIREMENTS}

The most important requirement of any radioactive material transportation system used on the Hanford Site is that it must be certified to transport Type B radioactive material per 49 CFR 173 (supernatant and sludge). A Hanford site requirement is that it must have enough shielding so as not to subject operations personnel to radiation levels greater than those permitted by ALARA Administrative Controls (FDH 1998b). Also, radiation contact levels must remain below $1 \mathrm{mrem} / \mathrm{h}$. Additional design requirements are listed below in order of importance:

- The container must be able to ship $500 \mathrm{ml}$ grab sample bottles.

- It should be a user-friendly system (not complex, easy to use).

- The container system should be able to transport a maximum number of grab sample bottles at a time in order to reduce costs.

- The weight of the Shipping Container should be less than $100 \mathrm{lb}$.

- The cradle to grave costs should be minimized compared to other transportation systems. 


\subsubsection{METHODS OF TRANSPORTATION}

Currently, the only authorized method of transporting $500 \mathrm{ml}$ grab sample bottles on-site is to use the Pig Shipping Container System with a SAFESEND inside. This system allows the transportation of one $500 \mathrm{ml}$ grab sample bottle per truck. Due to the lack of shielding provided by the SAFESEND, it is certified to transport limited Type B radioactive material only. Tanks to be sampled must be reviewed on a case-by-case basis before they can be sampled. This fact limits the number of radioactive waste tanks that can be sampled on-site since many samples would require shipment of sludge (a Type B radioactive material).

Another possible method of transporting $500 \mathrm{ml}$ grab sample bottles would be to use the Doorstop Shipping Container System. This system would require updating of the safety analysis report (FDH 1998d) and revising the Paint Can. The Doorstop Shipping Container System and the Paint Can may require further updating to address shielding issues.

A proposed method of transporting $500 \mathrm{ml}$ grab sample bottles is to use the Pig Shipping Container System with the PAS-1 Steel Pig inside. This method would provide the required shielding and containment necessary for transporting all Type B radioactive material (supernatant or sludge). Also, two $500 \mathrm{ml}$ grab sample bottles could be transported per truck.

\subsection{ASSUMPTIONS}

The only assumption made in the preparation of this document is the number of grab samples made per year. The number of grab samples was conservatively estimated at 15 to 20 over the next 20 years and the volume will predominantly be $125 \mathrm{ml}$.

\subsection{ALTERNATIVES}

\subsubsection{SAMPLE PIG}

The sample pig is not a viable means of transporting $500 \mathrm{ml}$ grab sample bottles due to the fact that a $500 \mathrm{ml}$ grab sample bottle will not fit in the Sample Pig cavity and the sample pig can not be modified to hold a $500 \mathrm{ml}$ grab sample bottle. Also, the Sample Pig Safety Analysis Report (SARP) would have to be re-certified. The cost associated with re-certification of the Sample Pig SARP is conservatively estimated at approximately $\$ 12$ to $\$ 20$ thousand to revise the SARP and $\$ 90$ to $\$ 100$ thousand to redesign the modified sample pig to ship $500 \mathrm{ml}$ and $125 \mathrm{ml}$ samples. 


\subsubsection{SAFESEND}

The SAFESEND is used in combination with either the Pig Shipping Container System or Hedgehog Shipping Container System and can be used to transport either one $1 \mathrm{~L}$ or one $500 \mathrm{ml}$ grab sample (depending on the Shipping Container System). The SAFESEND container is certified for transportation of limited Type $B$ radioactive material when used with the Pig Shipping Container System. The limited Type B certification would require review of each tank to be sampled. Some samples could not be transferred due to the high radioactivity and limited shielding.

The Hedgehog Shipping Container System uses the SAFESEND exclusively as an internal container. However, the SAFESEND can only be used a total of eight times in the Hedgehog Shipping Container System. This is controlled by affixed stickers. After all eight stickers have been removed from the SAFESEND the Hedgehog Shipping Container System can no longer be used to transport samples off-site, however, the lack of stickers does not prevent the use of the SAFESEND/Pig Shipping Container System combination to transport grab samples on-site. In this case the SAFESEND/Pig Shipping container System combination can be used an unlimited number of times.

The inside of the SAFESEND is bonded with a treated absorbent material. If the absorbent material becomes discolored (turns dark blue) the SAFESEND must be removed from service. The lid of the SAFESEND has a plastic locking mechanism. After several uses this mechanism tends to break rendering the SAFESEND unusable. Also, the vendor no longer makes the SAFESEND, therefore, no replacements can be ordered.

\subsubsection{PAS-1 STEEL PIG}

The PAS-1 Steel Pig, although expensive initially, approximately 945 man hrs (see Figure 3), can be used to transport either a single $500 \mathrm{ml}$ grab sample bottle or two $125 \mathrm{ml}$ grab sample bottles. Also, two $500 \mathrm{ml}$ grab sample bottles can be transported per transportation vehicle. The other systems are limited to one $500 \mathrm{ml}$ grab sample bottle per transportation vehicle. The PAS-1 Steel Pig provides additional shielding and is certified to transport all Type B radioactive material (Supernatant and Sludge).

Figure 3 contains a cost estimate (in man-hours) of the tasks required to make the PAS-1 Steel Pig an acceptable means of transporting $125 \mathrm{ml}$ and $500 \mathrm{ml}$ grab samples. The total includes the purchase of 20 new PAS-1 Steel Pigs for $\$ 40,000$ or $\$ 2,000 / \mathrm{Pig}$. 


\begin{tabular}{|l|r|r|}
\hline \multicolumn{1}{|c|}{ TASK DESCRIPTION } & WMFSNW & \multicolumn{1}{|c|}{ LMHC } \\
\hline Engineering Task Plan Preparation & 5 & 80 \\
\hline $\begin{array}{l}\text { ECN to Update WHC-SD-TP-SARP-OO1 to } \\
\text { include the use of the PAS-1 Steel Pig }\end{array}$ & 110 & 40 \\
\hline $\begin{array}{l}\text { Update procedures to use the steel PAS-1 Steel } \\
\text { Pig }\end{array}$ & 40 & 100 \\
\hline Purchase 20 PAS-1 STEEL PIGs or 20 new Pigs & 40 & 0 \\
\hline Field testing of the PAS-1 Steel Pigs & 0 & 100 \\
\hline $\begin{array}{l}\text { Preliminary design of the 125 ml sample insert } \\
\text { holder for the PAS-1 Steel Pig }\end{array}$ & 80 & 20 \\
\hline $\begin{array}{l}\text { ECN to update WHC-SD-TP-SARP-00l to } \\
\text { include the use of the 125 ml sample bottle holder } \\
\text { to hold two or more 125 ml sample bottles in the } \\
\text { Pig }\end{array}$ & 110 & 40 \\
\hline $\begin{array}{l}\text { Purchase the 125 ml sampler insert holders } \\
\text { Update the procedures to use the 125 ml sample } \\
\text { holder for the PAS-1 Steel Pig }\end{array}$ & 40 & 0 \\
\hline
\end{tabular}

Figure 3: PAS-1 Steel Pig Cost Estimate (in Man Hours)

\subsubsection{DOORSTOP SHIPPING CONTAINER SYSTEM}

Physically, the Doorstop Shipping Container System and Paint Can combination is large enough to transport $500 \mathrm{ml}$ grab sample bottles, however, this would require modification of the Paint Can. Any modifications to the Paint Can would result in a reduction of shielding and this transportation system is currently certified for the transportation of Type B radioactive material only. Modifications to the Paint Can would require re-certification of the SARP (FDH 1998d). The cost associated with re-certification of the Doorstop Shipping Container System is conservatively estimated at approximately $\$ 20$ to $\$ 30$ thousand and an additional $\$ 90$ to $\$ 100$ thousand to redesign the modified Paint Can.

\subsubsection{HEDGEHOG SHIPPING CONTAINER SYSTEM.}

Currently, the Hedgehog Shipping Container System can only transfer $500 \mathrm{ml}$ or $1 \mathrm{~L}$ grab sample bottles that are certified for Transportation of Type A radioactive material only. In order to transport the Type B radioactive material (sludge) in $500 \mathrm{ml}$ grab sample bottles on the Hanford Site the Hedgehog Shipping Container System would have to be modified to support the transportation of $500 \mathrm{ml}$ grab sample bottles. Shielding would have to be added and then the modified shipping package would need to be re-certified to meet DOT requirements. The cost associated with re-certification of the Hedgehog Shipping Container System only is conservatively estimated at approximately $\$ 4$ to $\$ 5$ million and would take approximately three years to complete. The likely number of $500 \mathrm{ml}$ grab 
samples per shipment is estimated at approximately four to five. Due to the cost and time required, the Hedgehog Shipping Container System is not a viable transportation system for $500 \mathrm{ml}$ grab sample bottles.

\subsubsection{COMMERCIALLY AVAILABLE ALTERNATIVES}

Several commercially available packaging methods capable of transporting $500 \mathrm{ml}$ grab sample bottles were reviewed by Waste Management Northwest. Each packaging method would require significant modification to the existing Pig Shipping Container System or Doorstop Shipping Container System. After modification, both of these systems would require re-certification for transportation of Type $B$ radioactive material. The cost of re-certification is conservatively estimated at $\$ 4$ to $\$ 5$ million and would take approximately three years to complete. Due to the required modification, the cost and the amount of time required, commercially available alternatives are not a viable option for transportation of $500 \mathrm{ml}$ grab sample bottles.

\subsection{DISCUSSION OF PREFERRED ALTERNATIVE SOLUTION}

The preferred alternative is the PAS-1 Steel Pig. The PAS-1 Steel Pig is from the PAS-1 Cask Transportation System and was found to fit inside the Sample Pig Shipping Container. Analysis of the PAS-1 Steel Pig shows that it will accommodate both the weight and shielding requirements for current sampling activities with volumes up to $500 \mathrm{ml}$. The PAS-1 Steel Pig will also accommodate two $125 \mathrm{ml}$ grab sample bottles. The PAS-1 Steel Pig when used with the Pig Shipping Container System would be capable of transporting all Type B radioactive material on the Hanford Site in accordance with HNF-PRO-154 (FDH 1998a) and HNF-PRO-157 (FDH 1997).

\subsection{NO ACTION ALTERNATIVE}

If no action is taken eventually the $500 \mathrm{ml}$ grab sample bottles will no longer be transportable. Either the SAFESEND lids will crack, all eight stickers will be removed, or the inside of the SAFESEND will become wet. All of these problems will render the SAFESENDs unusable and, since they are no longer manufactured, the broken SAFESENDs cannot be replaced. Also, continued use of the remaining SAFESENDs will subject field-sampling workers to high whole body doses due to the lack of shielding. For these reasons, it is recommended that the SAFESENDs be replaced with the PAS-1 Steel Pig. 
HNF-3707, Rev. 0

\subsection{REFERENCES}

FDH, 1997, HNF-PRO-157, Radioactive Material/Waste Shipments, Fluor Daniel Hanford, Inc., Richland, Washington.

FDH, 1998a, HNF-PRO-154, Responsibilities and Procedures for all Hazardous Material, Fluor Daniel Hanford, Inc., Richland, Washington.

FDH, 1998b, HNF-PRO-1629, ALARA Administrative Control Levels, Fluor Daniel Hanford, Inc., Richland, Washington.

FDH, 1998c, Safety Analysis Report for Packaging (On-site) Sample Pig Transportation System, WHC-SD-TP-SARP-001, Rev. 1-B, Fluor Daniel Hanford, Inc., Richland, Washington.

FDH, 1998d, Safety Analysis Report for Packaging (On-site) Doorstop Sample Carrier System, HNF-SD-TP-SARP-023, Rev. 0C, Fluor Daniel Hanford, Inc., Richland, Washington.

LMHC, 1998, Engineering Task Plan for using PAS-1 PIG in Sample PIG Transport System, HNF-3476, Lockheed Martin Hanford Company, Richland, Washington.

US CFR, 1998, 49 CFR 173, Shippers-General Requirements for Shipments and Packagings, US Code of Federal Regulations, as amended.

WHC, 1995, Operating and Maintenance Instrucktions for the Hedgehog Sample Package A DOT 7A Type A Package, WHC-SD-TP-OMM-002, Revision 0, Westinghouse Hanford Company. 
HNF-3707, Rev. 0

APPENDIX A: SHIPPING CONTAINER SYSTEM COMPARISON

Page A-1 


\begin{tabular}{|c|c|c|c|c|c|c|}
\hline \multicolumn{7}{|c|}{ COMPARISON OF ON-SITE SHIPPING CONTAINER } \\
\hline $\begin{array}{c}\text { Shipping } \\
\text { Container System }\end{array}$ & $\begin{array}{l}\text { Shipping } \\
\text { Container }\end{array}$ & $\begin{array}{c}\text { Certified for } \\
\text { Transportation of } \\
\text { Type B Radioactive } \\
\text { Material }\end{array}$ & $\begin{array}{c}\text { Certified for } \\
\text { Transportation of } 500 \mathrm{ml} \\
\text { Grab Sample Bottles and } \\
\text { Number per Vehicle }\end{array}$ & $\begin{array}{c}\text { Certified for Shipping of } \\
125 \mathrm{ml} \text { Grab Sample } \\
\text { Bottles and Number per } \\
\text { Vehicle }\end{array}$ & Purchase & Fabricate \\
\hline \multirow{3}{*}{$\begin{array}{c}\text { Pig Shipping } \\
\text { Container System }\end{array}$} & Sample Pig & $\bar{Y}$ & $\overline{\mathrm{N}}$ & $\mathrm{Y} / 2$ & $\mathrm{~N}$ & $\bar{Y}$ \\
\hline & SAFESEND & $\mathrm{Y}^{*}$ & $\mathrm{Y} / 1^{*}$ & $\mathrm{Y} / 2$ & $\bar{Y}$ & $\mathrm{~N}$ \\
\hline & PAS-1 Pig & $\mathrm{Y}$ & $\mathrm{Y} / 2$ & $\mathrm{Y} / 4$ & $\mathrm{Y}$ & $\bar{Y}^{*}$ \\
\hline $\begin{array}{l}\text { Doorstop Shipping } \\
\text { Container system }\end{array}$ & Paint Can & $\mathrm{Y}$ & $\mathrm{N}$ & Must be evaluated & $\mathrm{Y}$ & $\mathrm{N}$ \\
\hline $\begin{array}{c}\text { Hedgehog } \\
\text { Shipping } \\
\text { Container System }\end{array}$ & SAFESEND & $\mathrm{N}$ & $\bar{N}$ & Y (Type A only) & $\mathrm{N}$ & $\mathrm{N}$ \\
\hline
\end{tabular}

* $\quad$ limited Type B, must be evaluated on a case per case basis

** modifications must be made before use with Pig Shipping Container System 